\title{
Modeling of Gas Migration Through Low-Permeability Clay Rock Using Information on Pressure and Deformation from Fast Air Injection Tests
}

\author{
R. Senger ${ }^{1}(\mathbb{D}) \cdot$ E. Romero $^{2}(\mathbb{D}) \cdot$ P. Marschall $^{3}$
}

Received: 4 August 2016 / Accepted: 27 October 2017 / Published online: 3 January 2018

(C) The Author(s) 2017. This article is an open access publication

\begin{abstract}
The characterization of gas migration through low-permeability clay formations has been a focus of $R \& D$ programs for radioactive waste disposal, which is also of great importance for shale gas exploration, cap-rock behavior of hydrocarbon reservoirs, and $\mathrm{CO}_{2}$ sequestration. Laboratory tests have been performed on Opalinus Clay, a Mesozoic claystone that is being investigated in Switzerland as a potential host rock for the storage of nuclear waste. The laboratory program included specific water and air injections tests, as well as oedometer and isotropic compression tests. Undisturbed core samples have been retrieved from a shallow borehole in the Mont Terri Underground Research Laboratory (URL) and from a deep borehole in northern Switzerland. For the shallow cores from Mont Terri URL, largely linear-elastic deformations associated with the gas injection test could be inferred and the change in void ratio was accounted for by the pore compressibility. The corresponding change in permeability was obtained from the results of the water tests, indicating a log-linear relation between permeability and porosity. The derived porosity change and the corresponding change in permeability were implemented in the standard TOUGH 2 code, which reproduced the measured gas test results using fitted water retention data derived from laboratory measurements. Similar air injection tests performed on Opalinus Clay cores from the borehole at greater depth showed overall similar behavior, but at lower porosities, lower permeability values, and lower compressibility. These cases indicated nonlinear behavior which was implemented using an effective stress-dependent porosity change and the associ-
\end{abstract}

$凶$ R. Senger

rsenger@intera.com

E. Romero

enrique.romero-morales@upc.edu

P. Marschall

paul.marschall@nagra.ch

1 INTERA Incorporated, Austin, TX 78757, USA

2 Department of Civil and Environmental Engineering, Universitat Politècnica de Catalunya (UPC), Barcelona, Spain

3 NAGRA, Hardstrasse 73, 5430 Wettingen, Switzerland 
ated change in permeability. In addition, the anisotropy associated with the bedding planes of the clay formation was considered by assuming different properties for "soft" and "hard" layers to account for storage capacity for the injected gas prior to gas breakthrough. The computed change in the overall porosity could be compared to the measured axial deformation during the gas injection test and was used for calibration of the parameters describing the relationship between the effective stress and porosity, as well as the corresponding change in permeability and capillary pressure.

Keywords Two-phase flow - TOUGH2 code - Low-permeability clay · Gas injection · Deformation $\cdot$ Stress-dependency

\section{Introduction}

The characterization of gas migration through a low-permeability clay host rock for repositories is important because significant amounts of waste-generated gas mainly produced by anaerobic corrosion of metals and degradation of organic materials are expected to migrate from low- and intermediate-level waste (L/ILW) and high-level waste (HLW) repositories into the surrounding host rock (Nagra 2004, 2008). In order to assess the long-term safety of the repository, a comprehensive understanding of the relevant phenomena of gas and fluid flow through low-permeability clay rock is required. The National Cooperative for the Disposal of Radioactive Waste (Nagra), Switzerland has developed a comprehensive program to characterize gas flow in the Opalinus Clay (OPA), a Mesozoic claystone formation and one of the host rocks for a deep geological repository, through laboratory tests to determine the relevant hydraulic, geomechanical and two-phase properties, and to develop appropriate constitutive models through numerical analyses of the laboratory tests (Nagra 2009).

Understanding gas transport processes is an important issue in the assessment of radioactive waste repository performance, as well as for shale gas exploration, and cap-rock behavior of hydrocarbon reservoirs and $\mathrm{CO}_{2}$ sequestration. From the perspective of performance assessment, the impact of gas transport on the mechanical integrity and the associated hydraulic barrier function of the host rock needs to be evaluated. The actual gas migration mechanisms may entail standard two-phase flow or more complex mechanisms involving coupled two-phase geomechanical (Marschall et al. 2005) and possibly geochemical phenomena. Previous investigations of gas flow in the OPA focused on estimating the gas-entry pressures from gas tests on core samples (NAGRA 2002) and from packer tests in the Benken borehole at a depth of about $600 \mathrm{~m} \mathrm{bgl} \mathrm{(Marschall} \mathrm{et} \mathrm{al.} \mathrm{2005).} \mathrm{Similar} \mathrm{gas} \mathrm{tests} \mathrm{with} \mathrm{preced-}$ ing hydrotest were carried out in shallow boreholes at the Mont Terri Underground Research Laboratory (URL) (Marschall et al. 2003) that indicated dilatancy controlled gas flow (or "pathway dilation", terminology after Horseman et al. 1996). This dilatancy (expansion) involved an increase in the pore space or microfracturing at rising gas pressures, which resulted in an increase in intrinsic permeability.

In this study, laboratory tests on OPA cores from a shallow borehole ( $\sim 300 \mathrm{~m}$ depth $)$ in the Mont Terri URL and from the deep Schlattingen borehole in northern Switzerland (880 and $936 \mathrm{~m}$ depth) were performed by two laboratories. The Laboratory for Soil Mechanics at the Swiss Federal Institute of Technology in Lausanne focused on water retention behavior and geomechanical tests, which are described in Ferrari and Laloui (2013) and Ferrari et al. (2014). The Department of Civil and Environmental Engineering at the Universitat Politècnica de Catalunya (Spain) performed specific water permeability and air injection tests to determine 


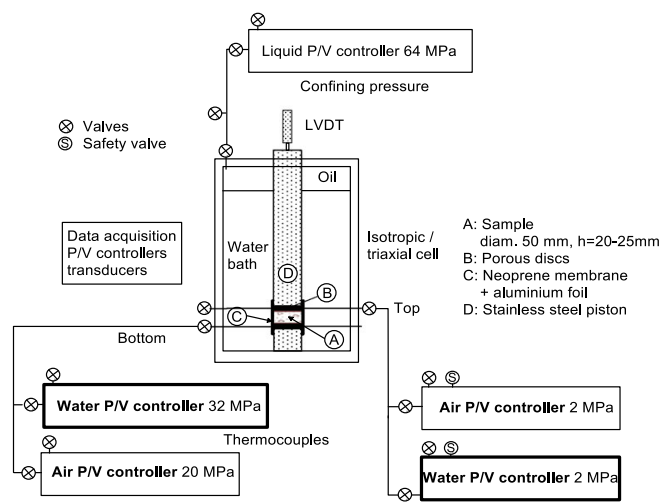

(a)

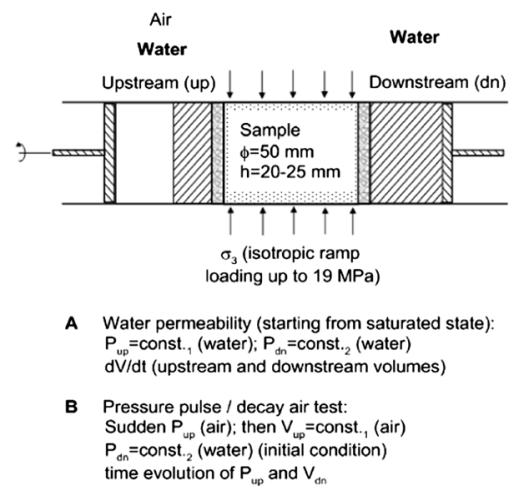

(b)

Fig. 1 Schematic of the test configuration for controlled-gradient water permeability tests and fast air injection tests followed by recovery period at constant volume showing a the triaxial cell and pressure volume (P/V) controllers, and $\mathbf{b}$ the specified conditions for the different tests (Romero et al. 2012b)

single-phase liquid and two-phase properties. Oedometer and isotropic compression tests were performed to study rock compressibility at different stress states and water permeability dependency on void ratio, which are described in detail by Romero et al. (2012a, b), Romero and Gomez (2013) and Romero and Gonzalez-Blanco (2015).

The following section describes the water and air injection test configuration and the specific results of the air injection tests performed on the shallow borehole from the Mont Terri URL. The numerical modeling of these tests was previously presented in Senger et al. (2014) and is summarized below. The previous study focused on standard two-phase flow analyses by using the measured injection pressures and outflow pressure responses for calibrating the two-phase flow properties using the laboratory-derived hydraulic and two-phase flow parameters as initial estimates for the inverse modeling of the air injection test responses using the ITOUGH2 code (Finsterle 2007). The measured axial deformation of these test was used to relate the inferred changes in hydraulic properties to changes in effective stress during the different stages of the tests.

In an extension of the previous analyses, the current analyses of the air injection tests from the deep Schlattingen borehole used an updated test configuration and took into account explicitly the measured deformation of the core sample during the air injection tests.

\section{Air Injection Tests on Shallow Cores}

The air injection tests were performed using a high-pressure triaxial cell, which was specifically designed to apply isotropic confining stresses and to inject water at specified gradients or inject air at a controlled volume rate while measuring the outflow at a downstream chamber. The axial deformation of the low-height core samples $(25 \mathrm{~mm}$ in height, $50 \mathrm{~mm}$ diameter), confined by several neoprene membranes and aluminum foils, was measured with an external LVDT transducer (no local radial transducers were installed due to experimental difficulties with the low-height specimen). A detailed description of the experimental setup for the different tests and analyses is given in Romero et al. (2012a, b). A schematic of the test configuration is shown in Fig. 1. 

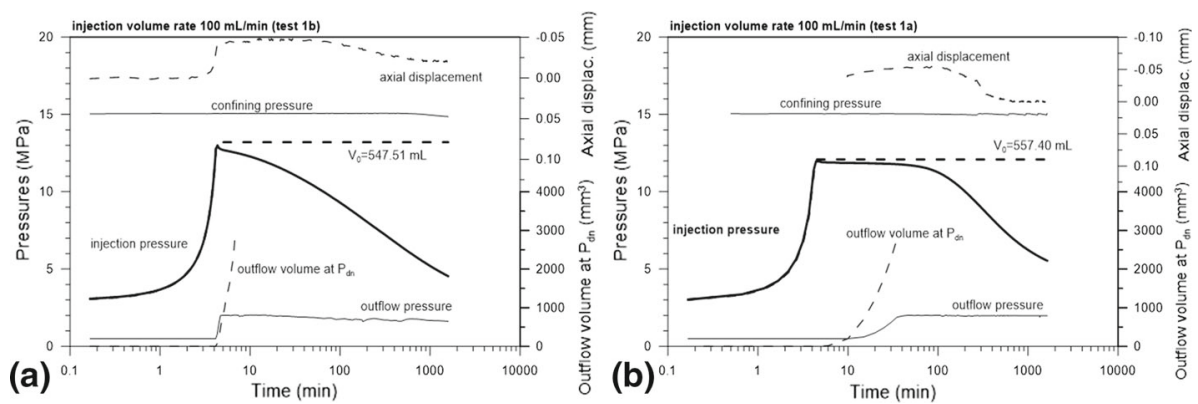

Fig. 2 Measured pressures at the injection and outflow sides together with outflow data and axial displacements for the air injection test parallel (a) and normal (b) to bedding for shallow OPA core sample (from Romero et al. 2012a, b)

For the water tests preceding the air injection tests, prescribed gradient conditions were used to determine the water permeability. For water tests under different confining isotropic stress conditions, the measured axial deformation on low-height specimen was used to estimate the change in void ratio and to derive a relationship between void ratio and stress, and the corresponding change in permeability as a function of changes in porosity. It was assumed that end restraint effects (contact of core with testing caps) induced negligible radial deformation in these low-height samples (only the contribution of axial strain is assumed to reflect the volumetric strain).

The time evolutions of air injection pressure during the fast controlled volume-rate air injection test at $100 \mathrm{~mL} / \mathrm{min}$ on two shallow OPA core samples with two bedding plane orientations (flow orthogonal and parallel to bedding) are shown in Fig. 2 together with the pressure/volume outflow response and axial displacement. The injection pressure increased up to about 12 and $13 \mathrm{MPa}$ (depending on the orientation), followed by a shut-in and recovery period. For the flow parallel to bedding, outflow response was observed immediately after shut-in, corresponding to a sudden drop in the injection pressure, followed by a subsequent gradual decline. The pressure in the fixed-volume outflow chamber rapidly increased until reaching $2 \mathrm{MPa}$, when a constant pressure was maintained through a release valve.

For the flow perpendicular to bedding, the injection pressure increased to $12 \mathrm{MPa}$ and remained relatively flat after shut-in (Fig. 2). The outflow response is significantly delayed compared to the case with flow parallel to bedding. Only after the apparent gas breakthrough did the injection pressure show a steep decline. This test indicated gas migration into the sample for certain time prior to gas outflow (i.e., gas breakthrough) at an injection pressure of $12 \mathrm{MPa}$, which is significantly below the fitted van Genuchten (1980) capillary air-entry parameter of $18 \mathrm{MPa}$ from the water retention data (Romero et al. 2012b).

The axial deformation revealed two different deformation regimes. For the test parallel to bedding (Fig. 2a), the initial pressure increase shows axial displacement at negative values indicating expansion. During the early period after shut-in, the pressure slightly decreased but the axial displacement continued showing expansive response. Afterward, as the pressure continued to decrease, the axial displacement reversed indicating compression as the effective stress increased.

For the gas test with flow normal to bedding (Fig. 2b), the axial displacement indicated a similar pattern, although no measurements were available during the early injection period. During the early period after shut-in, very little change in pressure occurred, whereas the axial displacement went negative indicating expansion. At late time, the axial displacement 
reversed as the pressure decline steepened indicating compression. The axial deformation, reflecting the changes in void ratio, indicated that during the injection period expansion and a corresponding increase in void ratio occurred associated with gas migration into the pore space of the core sample and effective stress decrease due to pore pressure increase. This expansion continued beyond the shut-in as the gas pressure front propagated into the sample causing the fluid pressure to increase and the effective stress to decrease. At late time after the pressure in the outflow chamber started to increase, the injection pressure declined and the effective stress increased, indicating compression.

For the analysis of the air injection tests, the test configuration was implemented in a numerical model using the two-phase flow code TOUGH2 (Pruess et al. 1999). In a first attempt, the measured results in terms of permeability, porosity, and pore compressibility, as well as the two-phase parameters derived from the water retention data were used as initial estimates for the inverse modeling using iTOUGH2 (Finsterle 2007), assuming viscocapillary two-phase flow. The resulting simulations could not reproduce well the observed injection pressure responses over the entire test and outflow responses for both air injection tests (parallel and normal to bedding). Moreover, the estimated parameters were significantly different from those derived from the measured retention curves and from the water tests, as described in detail in Senger et al. (2014).

A revised approach was then used taking into account the relationships between void ratio and stresses (Romero et al. 2012a). Changes in porosity are accounted for in the standard TOUGH 2 code through the pore compressibility, whereas the potential change in permeability is not. Assuming largely linear-elastic deformation associated with the gas injection test, the inferred change in void ratio can be accounted for by the pore compressibility. With the confining stress kept constant at $15 \mathrm{MPa}$ during the air injection tests, the variation in effective stress can be related to the variation in pressures. In TOUGH2 the effect of compressibility is accounted for by the change in porosity $(\mathrm{d} \phi)$ in response to a change in fluid pressure $(\mathrm{d} P)$ as:

$$
\mathrm{d} \phi=\phi C_{\mathrm{p}} \mathrm{d} P .
$$

Figure 3 a presents compressibility results on isotropic loading. The corresponding change in permeability was obtained from the results of the water tests, indicating a log-linear
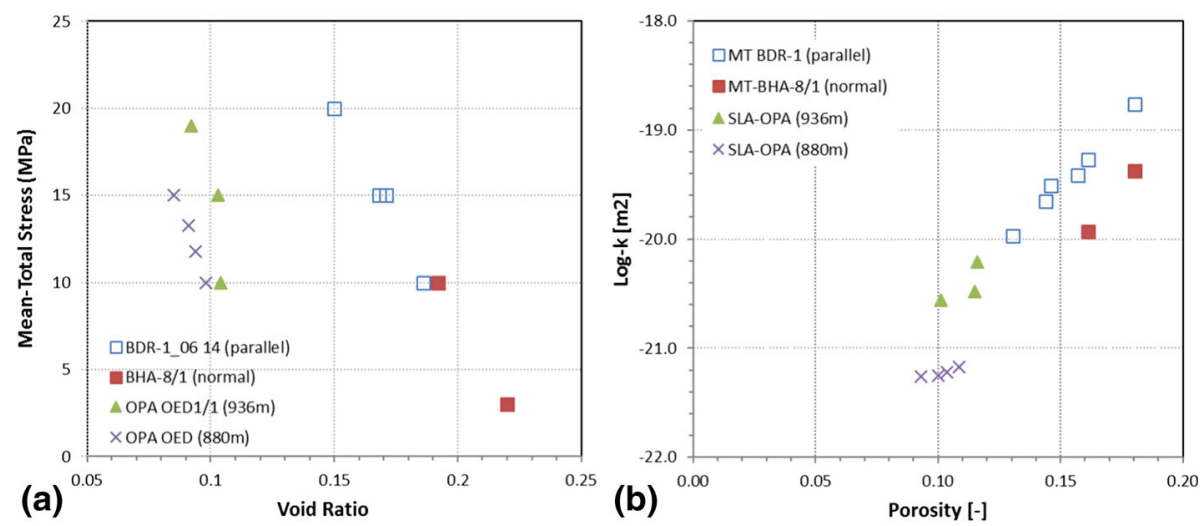

Fig. 3 a Compressibility properties during water tests, and $\mathbf{b}$ measured permeability values and porosities for water tests at different confining stresses for cores from shallow boreholes (MT) and from the deep borehole (SLA) (from Romero et al. 2012a, b; Romero and Gonzalez-Blanco 2015) 
Table 1 Model input parameters (shallow OPA)

\begin{tabular}{lll}
\hline & Test 1a parallel & Test 1 normal \\
\hline Permeability: $k\left(\mathrm{~m}^{2}\right)^{\mathrm{a}}$ & $1.4 \mathrm{E}-19$ & $4.3 \mathrm{E}-20$ \\
Porosity $(-)^{\mathrm{a}}$ & 0.20 & 0.18 \\
Pore compress. $C_{\mathrm{p}}(1 / \mathrm{Pa})^{\mathrm{a}}$ Eq. $(1)$ & $2.0 \mathrm{E}-08$ & $1.5 \mathrm{E}-08$ \\
van Genuchten: $P_{0}(\mathrm{~Pa})^{\mathrm{b}}$ & $18.0 \mathrm{E}+6$ & $18.0 \mathrm{E}+6$ \\
van Genuchten; $n(\mathrm{with} n=1 /(1-m))$ & 1.67 & 1.67 \\
Res. water saturation: $S_{\mathrm{lr}}^{\mathrm{c}}$ & 0.01 & 0.01 \\
Res. gas saturation: $S_{\mathrm{gr}}^{\mathrm{c}}$ & 0 & 0 \\
Initial saturation & 1 & 1 \\
\hline
\end{tabular}

${ }^{\text {a }}$ Measured

${ }^{\mathrm{b}}$ Fitted to WRC using van Genuchten/Mualem model:

$P_{\mathrm{c}}=P_{0} \cdot\left(S_{\mathrm{el}}^{-1 / m}-1\right)^{1-m} ; S_{\mathrm{el}}=\frac{S_{\mathrm{l}}-S_{\mathrm{lr}}}{1-S_{\mathrm{lr}}}$

$k_{\mathrm{rl}}=S_{\mathrm{el}}^{1 / 2} \cdot\left[1-\left(1-S_{\mathrm{el}}^{1 / m}\right)^{m}\right]^{2} ; S_{\mathrm{el}}=\frac{S_{\mathrm{l}}-S_{\mathrm{lr}}}{1-S_{\mathrm{lr}}}$

$k_{\mathrm{rg}}=\left(1-S_{\mathrm{eg}}\right)^{1 / 3} \cdot\left(1-S_{\mathrm{eg}}^{1 / m}\right)^{2 m} ; S_{\mathrm{eg}}=\frac{1}{1-S_{\mathrm{gr}}}$

c Assumed

relation between permeability and porosity (Romero et al. 2012a, b), which is presented in Fig. 3b.

For two-phase flow, the change in porosity/permeability also affected the capillary pressure, which was accounted for by the Leverett function (Leverett 1941), given as:

$$
P_{\mathrm{C}}=P_{\mathrm{C} 0} \frac{1}{\sqrt{k / k_{0}}},
$$

where $P_{\mathrm{C} 0}$ and $k_{0}$ are the reference values for capillary pressure and permeability, respectively.

For the revised analysis, only forward simulations were performed using the estimated permeability from the water test (Table 1); the two-phase parameters in the van Genuchten model (van Genuchten 1980) were fitted to the measured retention curve data and using the same shape parameter $(n)$ for the relative permeability functions (Mualem 1976). The results of the simulations for the air injection tests parallel and perpendicular to bedding planes are shown in Fig. 4. The simulation, incorporating the coupling between the changes in porosity due to pore compressibility associated with the increased pore pressure and the corresponding permeability changes, reproduced both the injection pressure response and the outflow pressure response. The peaks of the outflow response are due to the fact that the opening of the release valve at $2 \mathrm{MPa}$ was arbitrarily set at a certain time after the gas breakthrough response.

Figure 4 shows that the outflow response for the test perpendicular to bedding is significantly later than for the test parallel to bedding. That is, gas continues to migrate into the expanding pores prior to the breakthrough response. One can assume that preferential gas pathways are established resulting in higher gas mobility and less phase interference. This is represented by a Grant model for the gas relative permeability $k_{\mathrm{rg}}$ (e.g., $k_{\mathrm{rg}}=1-k_{\mathrm{rl}}$, where $k_{\mathrm{rl}}$ is the water relative permeability), which produced the more rapid injection pressure decline following the gas breakthrough.

The computed changes in permeability due to the changes in porosity within the core during the air injection test are shown together with the pressure and permeability profiles 

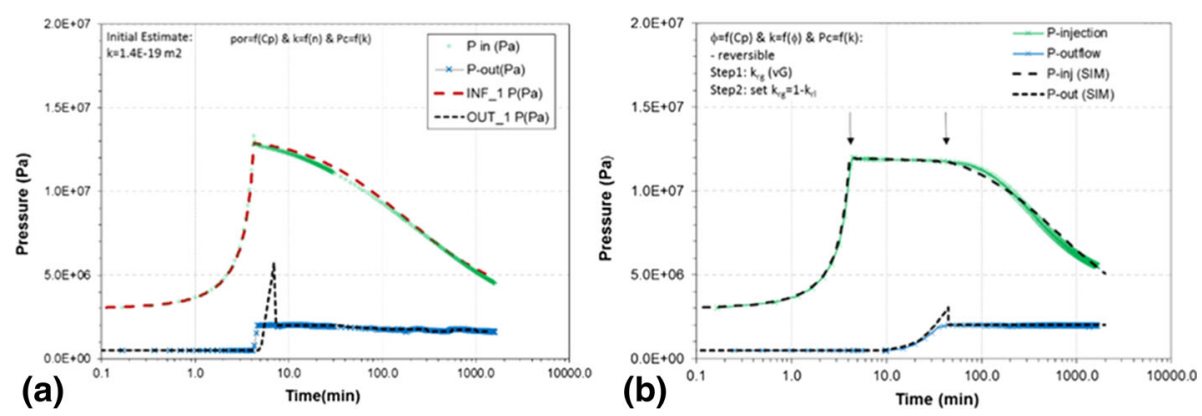

Fig. 4 Simulated (dashed lines) and measured (lines with symbols) pressures for air injection tests for flow parallel to bedding) (a), and for flow perpendicular to bedding (b) (modified from Senger et al. 2014); the arrows note the times for the profiles in Fig. 5
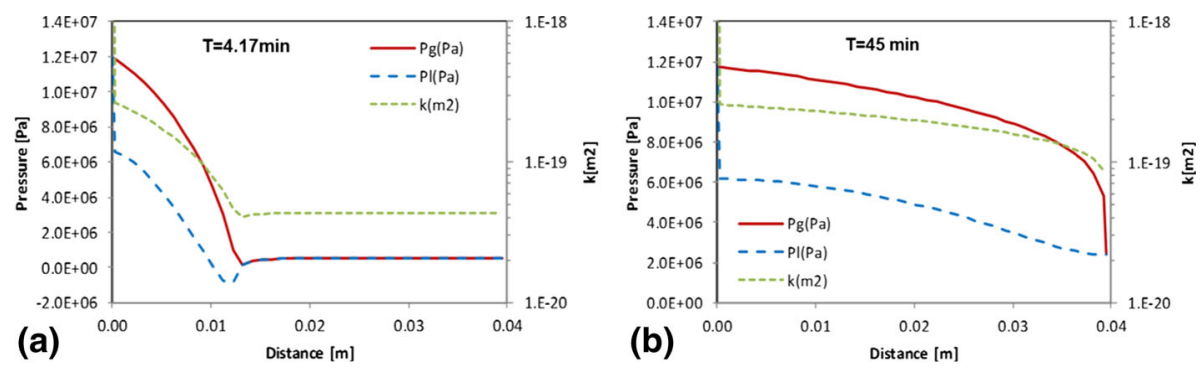

Fig. 5 Computed vertical profiles of gas pressure $\left(P_{\mathrm{g}}\right)$, liquid pressure $\left(P_{1}\right)$ and permeability $(\mathrm{k})$ throughout the core height (perpendicular to bedding) after $4.17 \mathrm{~min}$ (a) and $45 \mathrm{~min}$ (b)

in Fig. 5. After gas injection stopped (after $4.17 \mathrm{~min}$ ), the gas pressure profiles indicate the gas front migrating into the sample. The computed permeability increases from the initial $4.3 \mathrm{E}-20 \mathrm{~m}^{2}$ to $2.5 \mathrm{E}-19 \mathrm{~m}^{2}$ corresponding to an increase in porosity from 0.18 to about 0.21 which, in turn, correlates to the axial displacements, shown in Fig. 2. After 45 minutes - at about gas breakthrough - the increased permeability extends across the entire core corresponding to the maximum expansion of the core sample (Fig. 2).

\section{Air Injection Tests on Deep Cores}

The air injection tests on OPA core samples from a depth of about 880 and $936 \mathrm{~m}$ in the Schlattingen borehole in northern Switzerland showed overall similar responses (Fig. 6) as those from the shallow borehole at Mont Terri (Fig. 2). Only cores perpendicular to bedding were available from the deep borehole. Similar to the shallow analyses, a series of complementary tests were performed preceding the air injection tests, which included compression tests, water permeability tests and water retention measurements, as well as mercury intrusion porosimetry before and after the air injection test. These tests and associated analyses are described in detail in Romero and Gomez (2013) and Romero and GonzalezBlanco (2015).

The air injection tests in Fig. 6 were performed under isotropic stress conditions of 15 MPa for cores samples at two different depths of $880 \mathrm{~m}$ and $936 \mathrm{~m}$. Compared to the air injection tests on the shallow cores, the procedure of the deep tests was updated to measure 


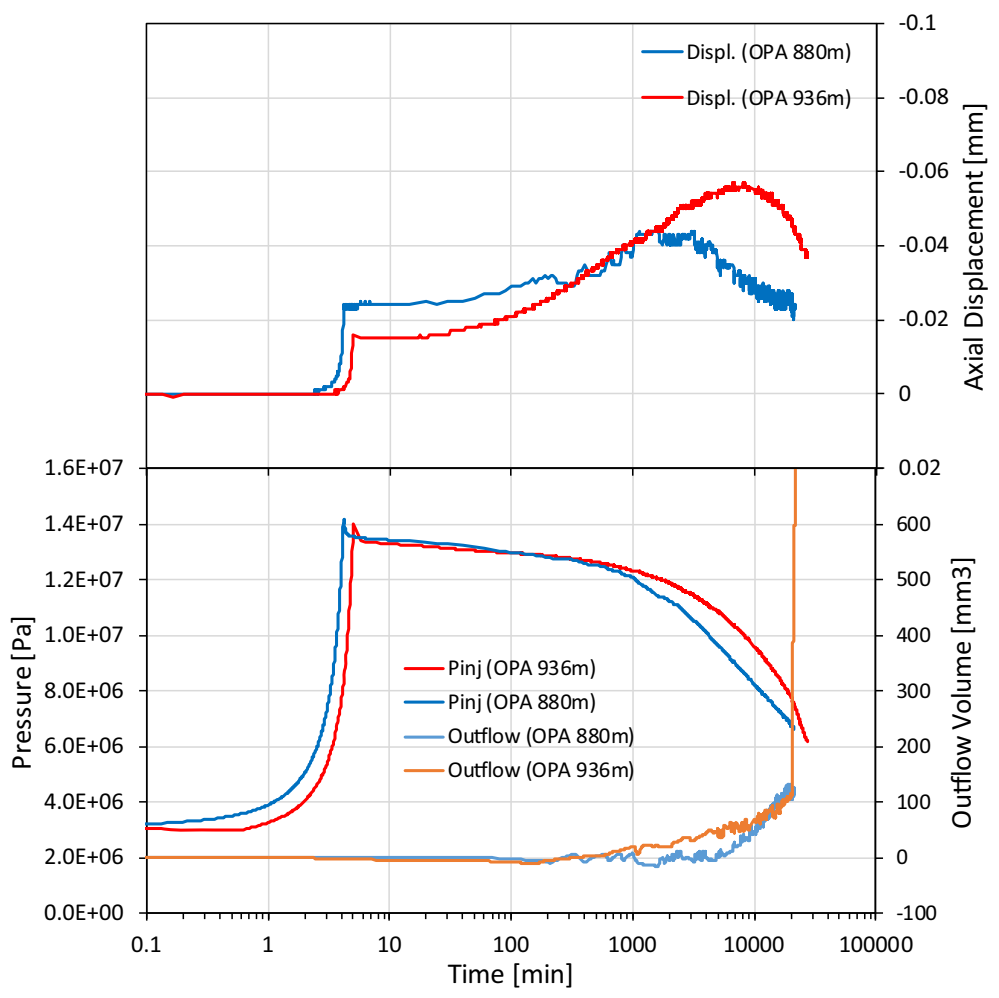

Fig. 6 Measured pressures at the injection side and outflow volumes at the downstream side together with axial displacements for the air injection test perpendicular to bedding for deep OPA core samples at 880 and $936 \mathrm{~m}$ (from Romero and Gomez 2013, and Romero and Gonzalez-Blanco 2015)

the actual outflow volume increase instead of the pressure increase which was limited to a maximum of $2 \mathrm{MPa}$. Even though the overall response was similar, the test on the deep cores indicated a significantly later outflow response (only after more than $100 \mathrm{~min}$ ) compared to the shallow air injection test (Fig. 2). Also, the injection pressure following shut-in showed a more distinct decline, indicating gas flow into the sample. That is, the injected gas has to accumulate in the core until outflow response occurs.

The axial deformation of the deep cores (Fig. 6) shows a similar response as those from the shallow cores (Fig. 2). However, the compressibility from the compression tests and initial porosity is much lower for the deep core samples than for the shallow core samples (Fig. 3). Potential non-reversible changes in the pore volume were indicated by the measured pore size distributions before and after the air injection tests, changing to a bimodal pore size distribution after the tests with new "pores" having two orders of magnitude higher entrance pore size (Romero and Gonzalez-Blanco 2015).

Table 2 summarizes the properties of the deep OPA core sample, indicating also higher suctions with a fitted van Genuchten parameter $P_{0}$ of 34 and $49 \mathrm{MPa}$ (Romero and Gomez 2013; Romero and Gonzalez-Blanco 2015). This information together with the additional parameters is used as input for the numerical modeling described below. 
Table 2 Model input parameters (deep OPA)

a Measured, ${ }^{\mathrm{b}}$ Fitted to WRC,

c Assumed

\begin{tabular}{ll}
\hline & OPA 936m (normal) \\
\hline Permeability: $k\left(\mathrm{~m}^{2}\right)^{\mathrm{a}}$ & $3.3 \mathrm{E}-21$ \\
Porosity: $\phi_{\mathrm{r}}(-)^{\mathrm{a}}\left(\phi_{o}\right)$ Eq. (3) & $0.1(0.125)$ \\
Pore compress. $C_{\mathrm{p}}(1 / \mathrm{Pa})^{\mathrm{a}}$ Eq. (1) & $1.0 \mathrm{E}-09$ \\
van Genuchten: $P_{0}(\mathrm{MPa})^{\mathrm{b}}$ & $34 / 49$ \\
van Genuchten; $n^{\mathrm{b}}$ & $1.58 / 2.05$ \\
Res. water saturation: $S_{\mathrm{lr}}^{\mathrm{c}}$ & 0.01 \\
Res. gas saturation: $S_{\mathrm{gr}}^{\mathrm{c}}$ & 0 \\
Initial saturation & 1 \\
Coefficient: $\alpha(1 / \mathrm{Pa})(\mathrm{soft}) \mathrm{Eq} .(3)$ & $1.0(0.8)$ \\
Factor for $k-\phi: c$ Eq. $(4)$ & 20 \\
Enhancement factor for $k_{\mathrm{g}}$ & 50
\end{tabular}

\section{Modeling Approach}

The observed responses from the deep core sample suggest more complex phenomena of gas migration through the clay implying nonlinear behavior associated with pathway dilation (new "pores" detected by mercury intrusion porosimetry after the gas tests).

For this analysis, the layering of the OPA is explicitly implemented by alternating layers of different material properties, allowing the soft layer to deform more than the stiffer layer, similar to the two-part Hooke's model described in Liu et al. (2009). This allows preferential gas migration into "softer" interlayers having somewhat higher porosity and correspondingly enhancing permeability before migrating to the next interlayer. The gas migration front in the axial direction is thus retarded and provides greater storage capacity for the observed gas flow into the sample prior to gas breakthrough.

For this study, the potential changes in hydraulic properties are described as a function of effective stress, using the empirical function given by Rutqvist et al. (2002):

$$
\phi=\phi_{\mathrm{r}}+\left(\phi_{0}-\phi_{\mathrm{r}}\right) \mathrm{e}^{-\alpha \sigma^{\prime}}
$$

where $\phi_{0}$ is zero effective stress porosity, $\phi_{\mathrm{r}}$ is the residual porosity at high effective stress, and the exponent $(\alpha)$ is a rock parameter that is used to represent the "stiff' layer $(\alpha=1)$ and the soft layer $(\alpha<1)$. Values of parameters are indicated in Table 2.

For relating the change in porosity to permeability, the exponential function given by Rutqvist et al. (2002) is used:

$$
k=k_{0} \mathrm{e}^{c\left(\frac{\phi}{\phi_{0}}-1\right)}
$$

where $k_{0}$ is the initial reference permeability and $c$ is a rock specific parameter (refer to Table 2).

In terms of the implementation in the TOUGH2 code, the change in porosity is computed from the effective stress that is determined from the simulated pressure and the confining stress:

$$
\sigma^{\prime}=\sigma_{T}-P
$$

where the confining stress is constant $\left(\sigma_{T}=15 \mathrm{MPa}\right)$, and the pressure $P$ represents the gas pressure under two-phase conditions and the liquid pressure under single-phase liquid 

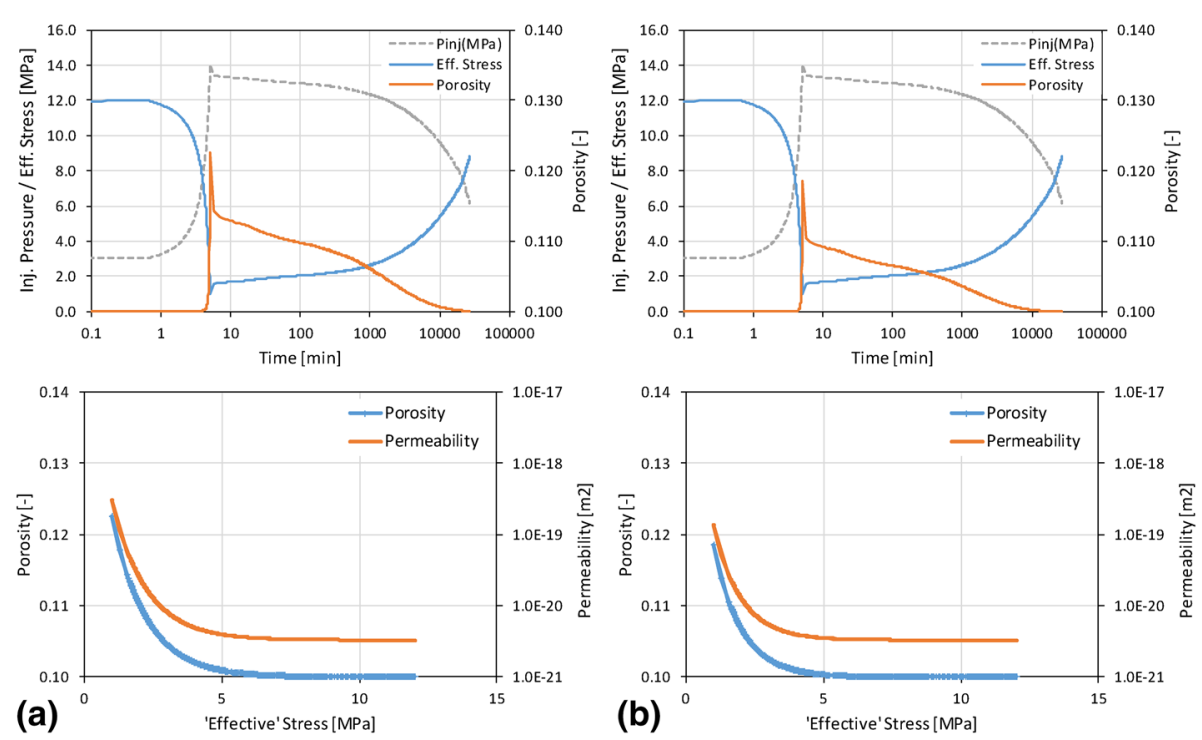

Fig. 7 Injection pressure, effective stress and computed porosity for two different values of $\alpha=0.8$ (a) and $\alpha=1.0$ (b) based on Eq.3 (top) and corresponding permeability based on Eq. 4 (bottom), representing the maximum changes at the upstream boundary of the core

conditions. The potential impact of two-phase conditions with high capillary suction on the effective stress as described in Nuth and Laloui (2008) is not considered.

The standard TOUGH 2 code considers a pressure-dependent permeability to account for the effect of gas slippage through the Klinkenberg function, which describes the change in gas permeability as a function of pressure for a given Klinkenberg parameter $b$, given as:

$$
k_{\mathrm{g}}=k_{\mathrm{g} 0}\left(1+\frac{b}{P}\right)
$$

This function was modified in previous approaches for implementing pressure-dependent permeabilities to account for pathway dilation associated with microfracturing in clay material (Calder et al. 2006; Senger et al. 2008). In the current study, the permeability change is related to the change in porosity (Eq. 4), which in turn is dependent of the effective stress (Eq. 3 ). Both equations were implemented as a separate option in TOUGH2, whereby both gas and liquid (or intrinsic) permeability can be considered. In addition, the permeability change can be assigned to different directions, allowing for anisotropy in the resulting permeability change.

Figure 7 (top) shows the effective stress response computed from the measured injection pressure and the confining stress of $15 \mathrm{MPa}$. The computed porosity as a function of effective stress assumed a parameter $\alpha=0.8$ and $1.0 \mathrm{~Pa}^{-1}$ for the "soft" and "stiff" layers, respectively (Table 2). The computed porosity shows a steep increase when the peak injection pressure and lowest effective stress is reached (Fig. 7 top), which compares to the volume expansion indicated by the steep axial displacement (Fig. 6). The observed axial displacement is directly related to the pore volume increase defined by the change in porosity due the increase in the pressure and corresponding decrease in effective stress (Eq. 3).

The corresponding change in porosity and permeability as a function of effective stress (Fig. 7, bottom) shows an exponential increase with decreasing effective stress. The perme- 
ability in Fig. 7 (bottom) depends largely on the coefficient (c) in Eq. (4) (refer to Table 2). As used in the previous modeling, the change in permeability results in a change in the capillary pressure using the Leverett scaling (Eq. 2). In addition, a separate enhancement factor for gas permeability is specified (refer to Table 2), which can be assigned to the different Cartesian directions. With these options, the enhanced gas permeability following breakthrough can be more realistically represented. As described above, the previous modeling of the air injection test for the shallow core samples oriented normal to bedding required a change in the gas relative permeability following gas breakthrough to account for higher gas mobility, which was represented by the Grant relative permeability (Fig. 4).

Compared to the previous air injection tests on the shallow OPA cores (Fig. 2, the boundary condition on the outflow was changed. In order to directly simulate the volume increase, a relatively high pore compressibility was assigned to the element representing the outflow chamber. Any mass flow of water and gas into the outflow chamber and corresponding pressure increase is represented by an increase in porosity according to Eq. (1), which can be converted to a volume increase for comparison with the measured volume increase in the outflow chamber. The outflow chamber was represented by a single element in the numerical model with a given volume based on the measured volumes of the outlet lines and the initial volume of the outflow chamber reported in Romero and Gonzalez-Blanco (2015). The change in porosity from the initial value of 1 can be calculated (Eq. 1) based on the pressure increase and a value for the pore compressibility representing the outflow chamber. In order to prevent the pressure in the outflow chamber to significantly increase, the pore compressibility has to be set to a large value $\left(C_{\mathrm{p}}=1.0 \mathrm{E}-5 \mathrm{~Pa}^{-1}\right)$.

\section{Simulation Results Using Random Heterogeneous Permeability}

In order to account for some variability in hydraulic properties of the core sample, the core was represented by a two-dimensional vertical cross-section model corresponding to the height $(25 \mathrm{~mm})$ and diameter $(50 \mathrm{~mm})$ and where the thickness was adjusted to yield the volume of the core sample. A two-dimensional random heterogeneous permeability field was generated to reproduce the typical variability of the Opalinus clay (Papafotiou et al. 2011), with a geometric average permeability of $3.3 \mathrm{E}-21 \mathrm{~m}^{2}$ corresponding to the measured value from the water test at $15 \mathrm{MPa}$ confining stress (Table 2). The heterogeneous permeability field is shown in Fig. 8 in terms of log-permeabilities, corresponding to a $\log _{10}\left(k_{\mathrm{avg}}\right)$ of $-20.48\left(k_{\mathrm{avg}}\right.$ in $\left.\mathrm{m}^{2}\right)$ and a standard deviation of 0.18 . Because of the relatively small range in measured porosities of the deep core samples (Fig. 3), a uniform initial porosity of 0.1 was used for both soft and stiff layers. The high-permeable top layer in Fig. 8 represents the high-porosity disk which is connected to a single element representing the outflow chamber. Initial conditions in the core and in the outflow line and chamber are fully water saturated at an absolute pressure of $0.6 \mathrm{MPa}$. The inflow chamber and inflow lines are air filled at an initial pressure of $3 \mathrm{MPa}$, and a constant injection rate of $100 \mathrm{~mL} / \mathrm{min}$ was applied by a mechanical piston to the injection chamber.

For the soft interlayers, the porosity increase was calculated using an ' $\alpha$ ' parameter of $0.8 \mathrm{~Pa}^{-1}$, compared to the stiff layers for which the parameter was set to $1.0 \mathrm{~Pa}^{-1}$ (Table 2 and Fig. 7). The increase in permeability for both layers was for both gas and liquid permeability. In addition, an enhancement factor for the gas relative permeability was also considered to account for the higher mobility when a gas path has developed (Table 2), but only parallel to 


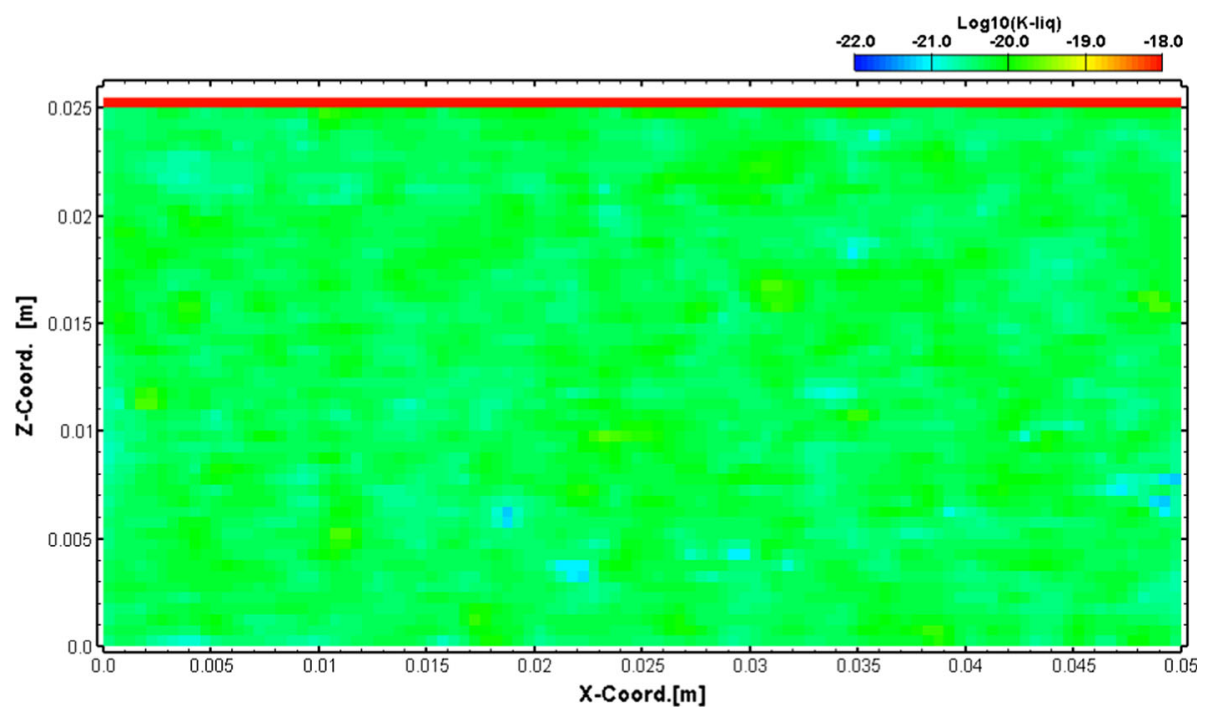

Fig. 8 Two-dimensional random permeability field (Log-k) based on a geometric average permeability of $3.3 \mathrm{E}-21 \mathrm{~m}^{2}$

bedding. This represented a permeability increase through microfracturing parallel to bedding which was expected to be air filled, due to the decrease in capillary pressures.

The results for this simulation are shown in terms of time evolutions of the simulated pressures at the injection chamber and outflow chamber (Fig. 9a), air inflow rates at the bottom of the core, and outflow rates of air and water at the top of the core (Fig. 9b), as well the axial displacement (Fig. 9c) and outflow volume (Fig. 9d). The simulated injection pressures follow the measured pressure during the constant-rate injection phase. However, after the shut-in, the simulated injection pressures remained nearly constant to about 1,000 minutes when the injection pressure started to decrease with a similar slope (in semilog scale) as the measured pressure but at a higher pressure level (Fig. 9a). The simulated outflow pressure showed only a small increase, which allowed computing the porosity increase and corresponding volume increase in the outflow chamber for comparison with the measured outflow volume increase (Fig. 9d). The measured outflow volume was converted to an equivalent volumetric rate for comparison with the simulated flow rates of air and water out of the core sample (Fig. 9b). In addition, the flow rate of gas into the core sample following the shut-in was estimated from the measured injection pressure decline, based on the ideal gas law given the remaining volume in the injection chamber. The derived flow rates show relatively large variations due to the variation in the measured pressure responses, and are only used for a qualitative comparison with the simulated flow rates.

The simulated flow rate of air into the core sample indicates a steep increase to a peak of about $1 . \mathrm{E}-7 \mathrm{~kg} / \mathrm{s}$ at shut-in followed by a steep decline to about $1 . \mathrm{E}-9 \mathrm{~kg} / \mathrm{s}$ after 100 minutes. Whereas the peak rate compares to the early injection rate into the sample calculated from the pressure decline after the shut-in, the subsequent flow rate significantly underestimated the measured rate. In comparison, the simulated outflow rates show similar pattern at later time, whereby the flow rate calculated from the test outflow volume represents a volumetric rate of the air-water mixture, whereas the simulation shows mass flow rates of air and water (Fig. 9d). The computed and measured outflow volumes are in the same range, 

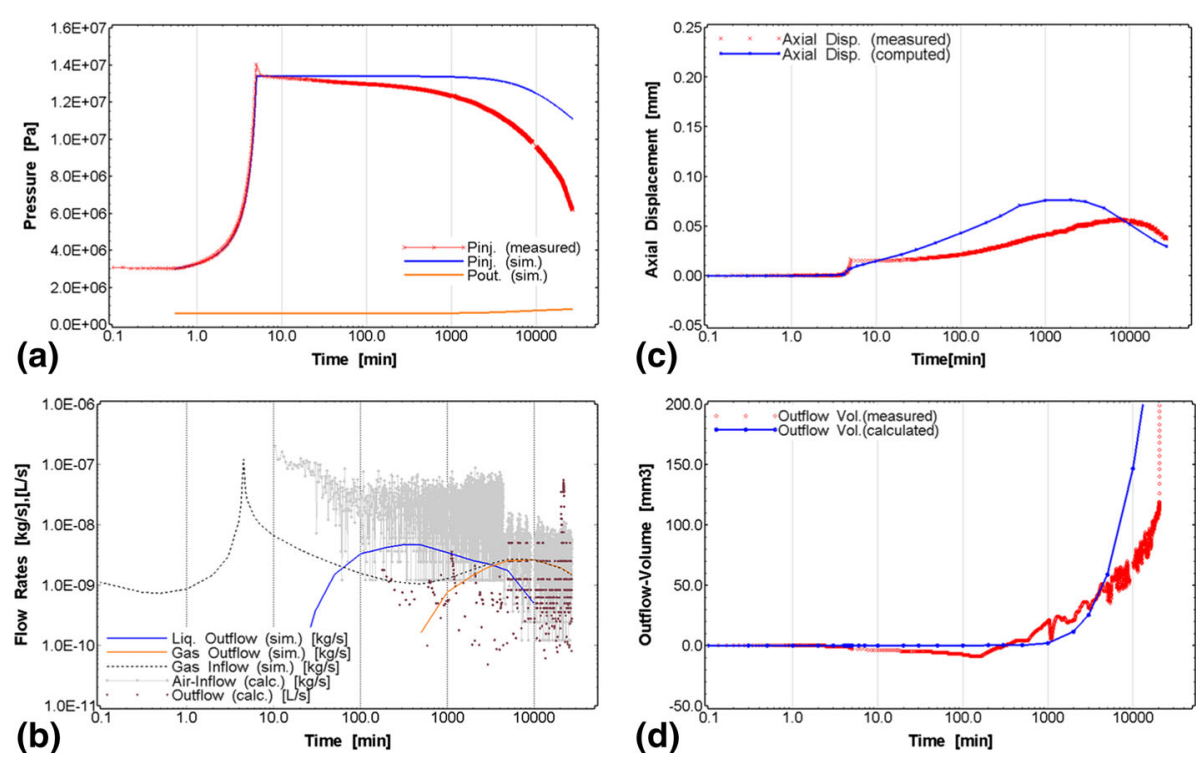

Fig. 9 Simulated and measured injection pressures (a), simulated and calculated flow rates (b), calculated and measured axial displacement (c), and calculated outflow volume increase for comparison with measured outflow volume increase $(\mathbf{d})$

except at late time where the computed volumes indicate a steeper increase, which can be related to higher injection pressures at late time compared to the measured pressures.

The computed porosity changes of the core sample and corresponding axial displacement reproduce the overall pattern in terms of volume expansion following the shut-in reasonably well; however, the early steep expansion could not be reproduced and the late time compression occurs slightly earlier (Fig. 9c).

The overall system response is depicted in more detail in Figs. 10 and 11 in terms of the spatial distribution of the different variables and at two different elapsed times. Figure 10 shows the simulated porosities, permeabilities and gas saturations after 300 minutes. The simulated porosities (Fig. 10a) show the layered pattern with higher porosities in the "soft" layers represented by the value of $\alpha=0.8 \mathrm{~Pa}^{-1}$ (Table 2) according to Eq. 3. The corresponding permeability increase is shown in terms of "liquid" permeability and "gas" permeability in Fig. 10c, d, indicating the significantly enhanced gas permeability, which is mostly in the horizontal direction corresponding to microcracks parallel to bedding in the "soft" layers. The vertical extend of the gas permeability distribution indicates the gas front in the core sample. The resulting gas saturation distribution shows the changes primarily in the soft layers associated with the increased porosity and particularly with gas permeability increase (Fig. 10b).

The simulation results after $3000 \mathrm{~min}$ are shown in Fig. 11, with gas saturations (a) and gas pressures (b), and computed gas flow velocities in terms of magnitude and flow patterns (c) and (d), respectively. The gas saturations show the heterogeneous distribution associated with the underlying permeability variations, which was enhanced by the porosity and corresponding permeability increases. The gas saturations in the top layer of the model indicate preferential outflow locations of gas flow. These locations may correspond to the observed spotted pattern observed at the top surface of the core sample after dismantling 


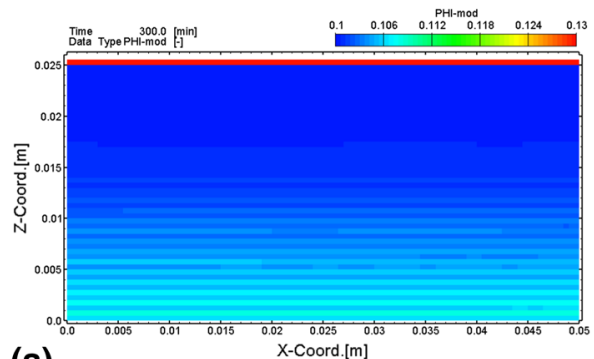

(a)
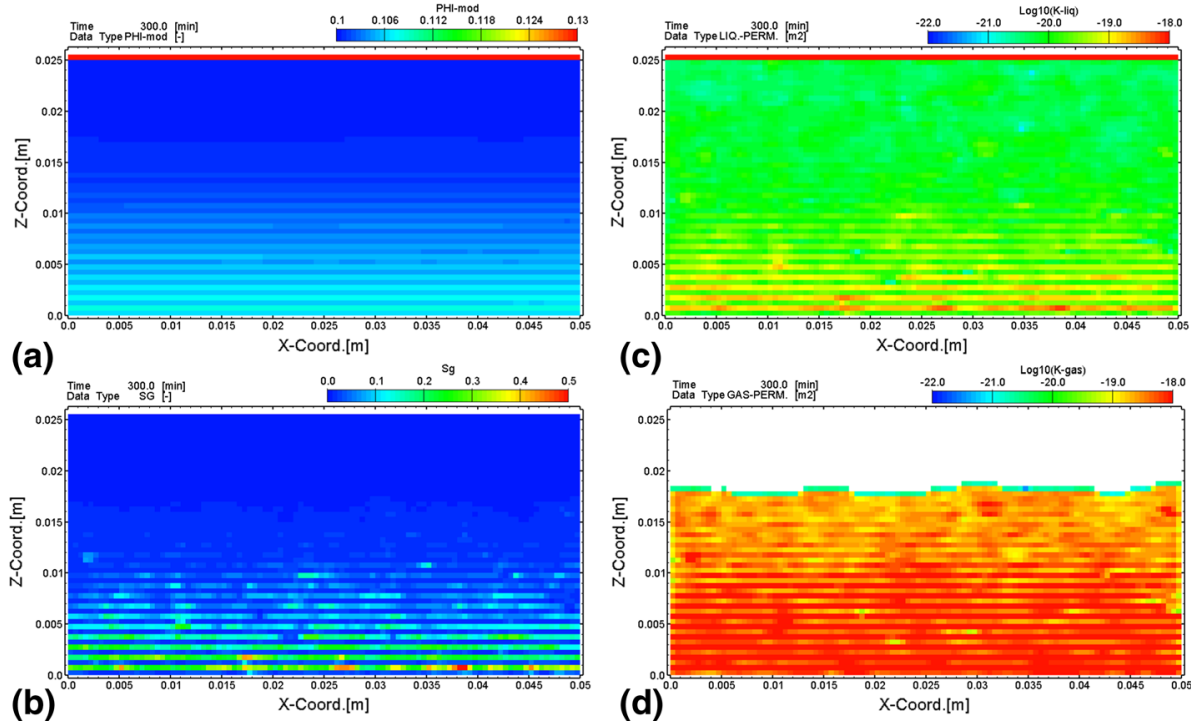

(c)

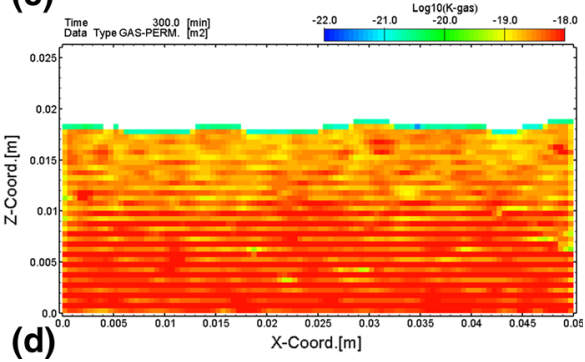

Fig. 10 Simulated distribution of porosity (a), gas saturation (b), liquid permeability (c) and gas permeability (d) after $300 \mathrm{~min}$

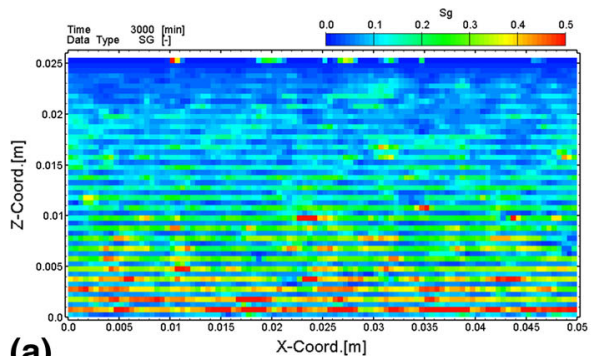

(a)
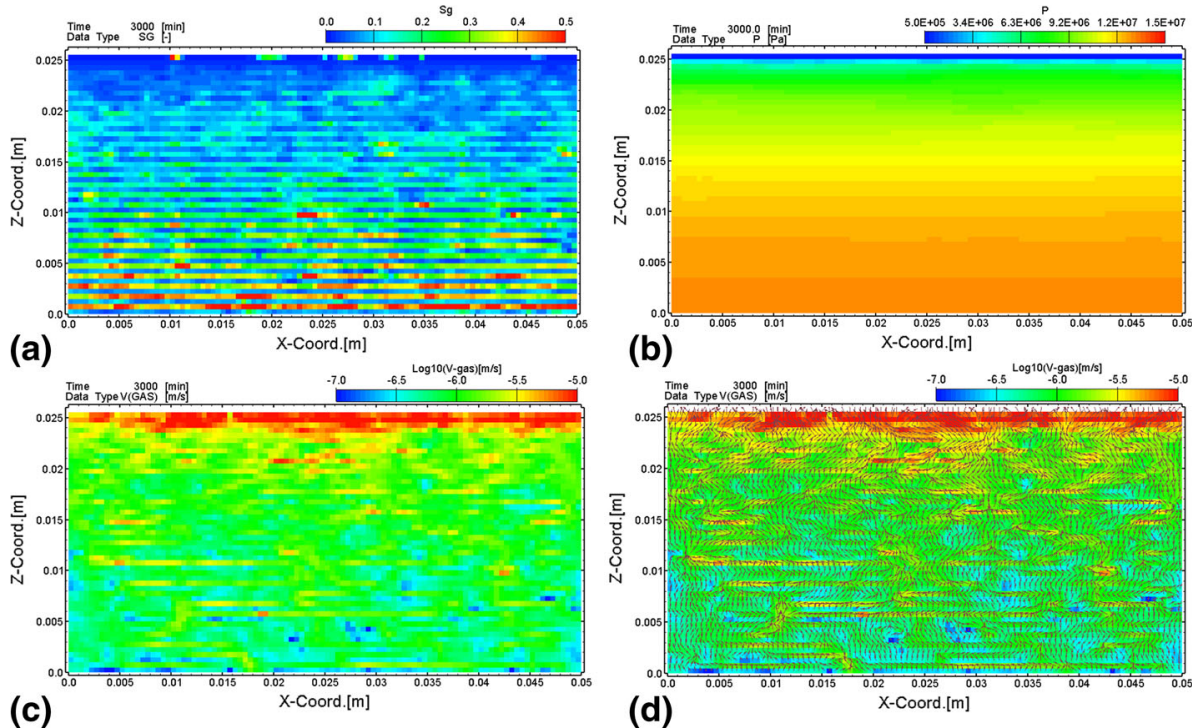

Fig. 11 Simulated distribution of gas saturation (a), gas pressure (b), and gas flow velocities (c), with computed gas flow vectors (d) after $3000 \mathrm{~min}$

(Romero and Gonzalez-Blanco 2015). Even though the gas pressure gradient is relatively uniform upward, the gas flow vectors show large variability in direction (Fig. 11d). 

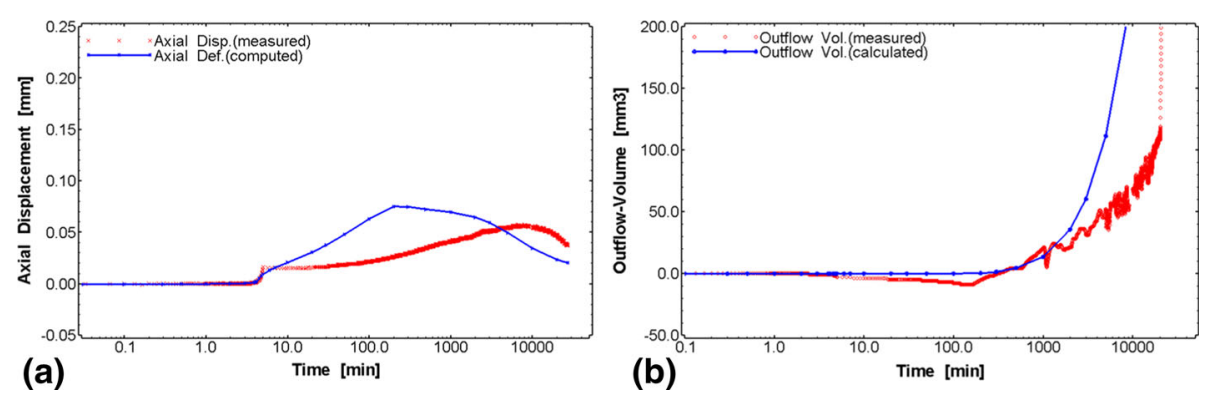

Fig. 12 Computed axial displacement and outflow volume based on simulation using the lower capillary strength parameter of van Genuchten $P_{0}=34 \mathrm{MPa}$

\section{Discussion and Conclusions}

The implementation of an effective stress-dependent porosity and corresponding permeability change can be used to reproduce the overall pattern of the measured injection pressure- and outflow responses, as well as the measured axial displacement. The approach used required representing the bedding of the Opalinus clay with alternating soft and stiffer materials allowing for different degrees of changes in porosity and permeability and associated anisotropy, particularly for the gas permeability. However, the model could not reproduce the gradual pressure decline following the shut-in and the steep increase in the axial deformation at peak injection pressure.

The measured axial displacement constrains the magnitude of maximum porosity increase, which can be controlled by the $\alpha$ and $\phi_{0}$ parameters in Eq. (3). The simulation results used a value $\phi_{0}=0.125$, representing the maximum porosity at zero effective stress. As shown in Fig. 6, smaller $\alpha$ values (soft layers) result in greater porosity increase. It can be shown, that the steep increase in axial displacement can be reproduced by increasing $\phi_{0}$ to 0.15 . However, this would significantly overestimate the maximum displacement at late times. The implemented anisotropy in gas permeability is required for the model to reproduce the delay of the outflow response. Romero and Gonzalez-Blanco (2015) showed some desaturation at the injection surface suggesting that some fissures were created in the near surface providing air pathways into the sample. This was indicated by the MIP measurements that were performed on the core samples after dismantling, which showed a significant shift of the water retention curve to lower saturations compared to the MIP prior to the air injection test (Romero and Gonzalez-Blanco 2015). Such fissures perpendicular to bedding near the injection surface could account for enhanced gas flow that would induce a greater pressure decline following shut-in.

The presented simulation case in Figs. 9, 10 and 11 used the higher van Genuchten air-entry parameter of $P_{0}=49 \mathrm{MPa}$ (Table 2), which produced a better fit of the axial deformation than when using the lower value of $34 \mathrm{MPa}$. This is better observed in Fig. 12 with a lower $P_{0}=34 \mathrm{MPa}$, which induced an earlier peak in the axial displacement and a somewhat earlier outflow volume response compared to that shown in Fig. 9. With all other parameters the same, the capillary effects do affect the propagation of the gas front through the sample and the corresponding deformation associated with the changes in porosity and permeability.

The detailed analyses of laboratory experiments on Opalinus Clay cores were used to develop and refine a conceptual and numerical model for simulating two-phase flow of gas through a low-permeability clay formation. The air injection tests complemented by isotropic 
compression tests, water permeability and water retention measurements provided consistent data sets, which are enhanced by the measured displacement during the air injection tests. The air injection test responses for the shallow OPA cores could be reasonably well reproduced assuming standard two-phase flow accounting for the change in porosity associated with the measured pore compressibility and for the change in permeability and capillary pressure. The results of the air injection tests of the deep OPA cores indicated overall similar behavior in terms of pressure responses and measured axial displacement as the shallow cores. However, the implied changes in porosity and permeability required more complex processes associated with the creation of additional pore space through pathway dilation. The implementation of effective stress-dependent porosity/permeability changes accounting for the layered structure of the Opalinus Clay assuming soft interlayers could reasonably well reproduce the overall hydraulic and geomechanical response. Refinement of the models to improve the fit include accounting for fissures normal to bedding at the injection surface to allow preferential gas flow into the sample following shut-in. Furthermore, the potential initial anisotropy of permeability and porosity may need further examination.

Acknowledgements This study has been performed under contract from the National Cooperative for the Disposal of Radioactive Waste (Nagra), Switzerland. The comments and suggestions of two anonymous reviewers were much appreciated.

Open Access This article is distributed under the terms of the Creative Commons Attribution 4.0 International License (http://creativecommons.org/licenses/by/4.0/), which permits unrestricted use, distribution, and reproduction in any medium, provided you give appropriate credit to the original author(s) and the source, provide a link to the Creative Commons license, and indicate if changes were made.

\section{References}

Calder, N., Avis, J., Senger, R., Leung, H.: Modifying TOUGH2 to support modeling of gas transport through saturated compacted Bentonite as part of the large-scale gas injection test (LASGIT) in Sweden. In: TOUGH2 Symposium 2006, Lawrence Berkeley National Laboratory, Berkeley, CA (2006)

Ferrari, A., Laloui L.: Advances in the testing of the hydro-mechanical behaviour of shales. In: Multiphysical Testing of Soils and Shales, SSGG, pp. 57-68. Springer, Berlin (2013)

Ferrari, A., Favero, V., Marschall, P., Laloui, L.: Experimental analysis of the water retention behaviour of shales. Int. J. Rock Mech. Min. Sci. 72, 61-70 (2014)

Finsterle, S.: ITOUGH2 User's Guide, Report LBNL-40040. Lawrence Berkeley National Laboratory, Berkeley, CA (2007)

Horseman, S.T., Higgo, J.J.W., Alexander, J., Harrington, J.F.: Water, gas and solute movement through argillaceous media. Nuclear Energy Agency Report CC-96/1, Paris, OECD, (1996)

Leverett, M.C.: Capillary behaviour in porous solids. Trans. AIME 142, 159-172 (1941)

Liu, H.H., Rutqvist, J., Berryman, J.C.: On the relationship between stress and elastic strain for porous and fractured rock. Int. J. Rock Mech. Min. Sci. 46, 289-296 (2009)

Marschall, P., Croisé, J., Schlickenrieder, L., Boisson, J.Y., Vogel, P., Yamamoto, S.: Synthesis of hydrogeological investigations at the Mont Terri site (Phases 1-5). Mont Terri Technical Report TR 2001-02, Geotechn. Inst. Ltd., Bern, Switzerland (2003)

Marschall, P., Horseman, P., Gimmi, T.: Characterization of gas transport properties of the Opalinus Clay, a potential host rock formation for radioactive waste disposal. Oil Gas Sci. Technol. 60, 121-139 (2005)

Mualem, Y.A.: New model for predicting the hydraulic conductivity of unsaturated porous media. Water Resour. Res. 12(3), 513-522 (1976)

NAGRA: Projekt Opalinuston-Synthese der geowissenschaftlichen Untersuchungs-ergebnisse. Entsorgungsnachweis für abgebrannte Brennelemente, verglaste hochaktive sowie langlebige mittelaktive Abfälle. Nagra Technical Report NTB 02-03, Nagra, Wettingen, Switzerland (2002)

NAGRA: Effects of post-disposal gas generation in a repository for spent fuel, high-level waste and long-lived intermediate-level waste sited in Opalinus Clay. Nagra Technical Report 04-06 (2004) 
NAGRA: Effects of post-disposal gas generation in a repository for low- and intermediate-level waste sited in the Opalinus Clay of Northern Switzerland. Nagra Technical Report 08-07 (2008)

NAGRA, The Nagra Research, Development and Demonstration (RD\&D) Plan for the Disposal of Radioactive Waste in Switzerland. Nagra Technical Report 09-06 (2009)

Nuth, M., Laloui, L.: Effective stress concept in unsaturated soils: clarification and validation of a unified framework. Int. J. Numer. Anal. Meth. Geomech. 32, 771-801 (2008)

Papafotiou, A., Senger, R., Alcolea, A., Lanyon, W., Ewing, J.: Modeling approaches for evaluating the effects of heterogeneity on two-phase flow associated with the migration of waste-generated gas from SF/HLW and L/ILW repositories in low-permeability formations. In: The 14th International Conference on Environmental Remediation and Radioactive Waste Management (ICEM), September, Reims, France (2011)

Pruess, K., Oldenburg, C., Moridis, G.: TOUGH2 User's Guide, Version 2.0, Report LBNL-43134. Lawrence Berkeley National Laboratory, Berkeley, CA (1999)

Romero, E., Gomez, R.: Water and air permeability tests on deep core samples from Schlattingen SLA-1 borehole; Material characterization and experimental set-up. Compressibility on loading, water permeability and air injection results, NAGRA Report NAB 13-51 (2013)

Romero, E., Gonzalez-Blanco, L.: Complementary water and air permeability tests on core samples from Schlattingen SLA-1 borehole. NAGRA Report NAB 15-06 (2015)

Romero, E., Senger, R., Marschall, P.: Air injection laboratory experiments on Opalinus Clay, experimental techniques, results and analyses. 3rd EAGE Shale Workshop, Barcelona, pp. 23-25 (2012a)

Romero, E., Senger, R., Marschall, P., Gómez, R.: Air tests on low-permeability claystone formations. Experimental results and simulations. In: Laloui, L., Ferrari, A. (eds.) Multiphysical Testing of Soils and Shales, pp. 68-83. Springer, Berlin (2012b)

Rutqvist, J., Wu, Y., Tsang, C., Bodvarsson, G.: A modeling approach for analysis of coupled multiphase fluid flow, heat transfer, and deformation in fractured porous rock. Int. J. Rock. Mech. Min. Sci. 39, 429-442 (2002)

Senger, R., Lanyon, B., Marschall, P., Vomvoris, S., Fujiwara, A.: Numerical modelling of the gas migration test at the Grimsel Test Site (Switzerland). Nucl. Technol. 164, 155-168 (2008)

Senger, R.K., Romero, E., Ferrari, A., Marschall, P.: Characterization of gas flow through low-permeability claystone: Laboratory and two-phase flow analyses. In: Norris, et al. (eds.) Clays in Natural and Engineered Barriers for Radioactive Waste Confinement, vol. 400. Geological Society, Special Publication, London (2014)

van Genuchten, MTh: A closed-form equation for predicting the hydraulic conductivity of soils. Soil Sci. Soc. Am. J. 44, 892-898 (1980) 